\title{
A Dual Measure of Uncertainty: The Deng Extropy ${ }^{\dagger}$
}

\section{Francesco Buono}

Dipartimento di Matematica e Applicazioni “Renato Caccioppoli”, Università degli Studi di Napoli Federico II, Napoli, Italy

† Presented at the Entropy 2021: The Scientific Tool of the 21st Century, 5-7 May 2021; Available online: https://sciforum.net/conference/Entropy2021/.

Published: 5 May 2021

Lad, Sanfilippo and Agrò (2015) introduced the extropy as the dual concept of entropy. This measure of uncertainty has attracted the interest of researchers, and several versions of the extropy have been studied in the literature. Moreover, in the context of the Dempster-Shafer theory of evidence, Deng studied a new measure of discrimination, named the Deng entropy. In this talk, we define the Deng extropy and study its relation with Deng entropy, and examples are proposed in order to compare them. The behaviour of Deng extropy is studied under changes of focal elements. A characterization result is given for the maximum Deng extropy and, finally, a numerical example in pattern recognition is discussed in order to highlight the relevance of the new measure.

\section{References}

1. Buono, F.; Longobardi, M. A Dual Measure of Uncertainty: The Deng Extropy. Entropy 2020, $22,582$.

2. Deng, Y. Deng entropy. Chaos Solition Fract. 2016, 91, 549-553.

3. Lad, F.; Sanfilippo, G.; Agrò, G. Extropy: Complementary dual of entropy. Stat. Sci. 2015, 30, 40-58.

(C) 2021 by the authors. Licensee MDPI, Basel, Switzerland. This article is an open access article distributed under the terms and conditions of the Creative Commons Attribution (CC BY) license (http://creativecommons.org/licenses/by/4.0/). 